Bentham OPEN

RESEARCH ARTICLE

\title{
Examining Student-teacher Relationship from Students' Point of View: Italian Adaptation and Validation of the Young Children's Appraisal of Teacher Support Questionnaire
}

\author{
C. Longobardi*, F.G.M. Gastaldi, L.E. Prino, T. Pasta and M. Settanni \\ Department of Psychology, University of Turin, Italy
}

Received: September 28, 2016

Revised: December 05, 2016

Accepted: December 06, 2016

\begin{abstract}
:
Background:

Numerous studies on educational and developmental psychology have concluded that students' affective relationships with their teachers are crucial for their academic motivation and commitment to school. Frequently the relationship is evaluated from the teacher's point of view, but the importance of considering the children's perspective has been highlighted by many authors.
\end{abstract}

\section{Methods:}

In this study, we present data to examine the factorial structure of the Young Children's Appraisals of Teacher Support (Y-CATS), a measure designed to explore children's perceptions of their relationships with teachers on a sample of 503 children ranging in age from 5 to 10 years, and 163 teachers.

\section{Results:}

This study provides implications for construct validity research and substantive research using Y-CATS, given that Y-CATS is used extensively in intervention and research in early childhood education.

\section{Conclusion:}

On the basis of the results obtained, the questionnaire seems to be an adequate instrument to study student-teacher relationships, both as a monitoring scale of a given relationship and as a way to help teachers achieve more awareness of their educational skills.

Keywords: Student-teacher relationship, Teacher-child relationship, Elementary school, Educational assessment, School psychology, Student perception, Italian validation.

\section{INTRODUCTION}

The student-teacher relationship is a focal relationship [1] that can considerably influence children's behavior and their socio-emotional and cognitive development [2 - 4]. It is one of the fundamental development contexts [5, 6], being an important resource for the development of adequate social skills [7, 8]. The literature in fact shows that the quality of this relationship is a decisive factor in pre-school and school-aged children's development of socio-emotional abilities [9 - 12], level of engagement and academic achievement [6,13], as well as the process of adaptation to the class [14] and in the integration of disabled [15 - 17] or foreign students [18].

Children that experience a secure relationship with the teacher, in fact, tend to display higher levels of pro-social

\footnotetext{
* Address correspondence to this author at the Department of Psychology, University of Turin, Via Po 14, 10123, Italy; Tel: +39 011 6703056; Fax:

+ 39011 8146231; E-mail: Claudio.longobardi@unito.it
} 
conduct, more sophisticated interactions while playing, and better emotional understanding compared to their peers. Current theories also underline the need to prepare students for school in a perspective of development centered around social relations [19]. The teacher plays a crucial role in the development of academic, socio-emotional and cognitive skills $[3,20]$. Although most of the research on the student-teacher relationship has been conducted exclusively from the teacher's standpoint, we cannot neglect the child's point of view, since it is a dyadic construct. Recent studies have tried to investigate the student-teacher issue from the child's viewpoint [11, $21-23]$, and our work, too, is in line with these recent studies.

\section{Student-Teacher Relationships: Theoretical Framework}

The student-teacher relationship has often been treated according to the multiple Attachment perspective, which holds that for children, especially younger ones, teachers act as "alternative caregivers" [24], and this relationship should be seen as an extension of the primary parent-child attachment [25]: being a "significant other" for the child, the teacher can also help to change the internal operative models developed on the basis of the attachment bond established with the mother, thus promoting new models of emotional and behavioral regulation $[6,26]$.

Such aspects can be understood in greater depth by considering them from the ecological systems standpoint [27, 28]: the quality of the student-teacher relationship is in fact influenced by the interaction between individual and enviromental factors, described from the perspective of dynamic systems and ecological models [29].

\section{Student-Teacher Relationship Perceptions: Multidimensional Construct}

Relationships between teachers and students can be considered as microsystems in which various factors of the child and the adult intertwine and are consolidated [30]. Many studies have drawn attention to the bi-directional perception that student and teacher have of their reciprocal relationship.

An effective tool to assess such perceptions was developed by Pianta [31], the STRS - Student-Teacher Relationship Scale. Its use enables the operator to consider three vital elements of the relationship: closeness, conflict and dependency. These aspects have been considered by researchers as the fundamental constructs required for measuring the relationship. Therefore, every new investigation instrument aims to evaluate these aspects.

Closeness is related to the aspect marked by affection, warmth and emotional involvement; moreover, it is considered a sign of the student's positive attitudes towards the school, schoolwork and those who share his or her school experience [9]. A relationship of closeness with the teacher would therefore enable the student to express him/herself freely without inhibitions or fear [32] and to work hard with better results. It would also facilitate the development of positive attitudes towards school and, above all, the acquisition of social skills [33]. Finally, relationships marked by closeness become a protective factor in development, especially in cases of maltreated or abused children, or those from unhappy families.

The aspect of conflict, on the other hand, shows the presence of conflictual relationships, or indicates the absence of gratifying relationships between teacher and student. This aspect is therefore believed to measure the degree of negativity in the relationship, becoming a stress factor for the child in class. Relationships marked by a high level of conflict can give rise to many behavioral problems [29], may also impede scholastic performance, reducing participation in learning activities to a minimum, and even compromise regular school attendance [7, 34]. Lastly, the aspect of dependency measures the level of dependency the child shows towards the teacher. A child that is overdependent on the teacher figure does not only express uncertainty and lack of confidence in schoolwork, but also the demand for approval and support. Inhibited in their explorations of the class/school environment, and incapable of establishing satisfactory relationships with their peers, they are afflicted by feelings of isolation and loneliness [9].

\section{Measuring Student-Teacher Relationship}

Few assessment tools on the student-teacher relationship have considered the student's viewpoint in kindergarten and the early years of elementary school.

Some authors have put forward an evaluation system of the child's relationship with his/her teacher using a system for coding children's drawings [21]. The children were asked to draw themselves and their teacher. The drawings were then coded using Fury's scheme for coding parent-child drawings [35]. The coding scheme considers eight global aspects of the quality of the relationship: vitality/creativity, family pride/happiness, vulnerability, emotional distance/ isolation, tension/anger, role reversal, bizarreness/dissociation and global pathology. The application of the graphic 
method proved to have validity. Children with characteristics of negativity revealed poor capacities to adapt to school [21].

Other researchers suggested using the narrative method with small children in order to identify the quality of the perceived relationship with their teacher. These methods prove useful in understanding the child's internal operative model, and they are mainly based on "story completion tasks", designed to assess the child's ability to solve stressful situations based on people's relationships to complete the story. Among the most recent narrative methods, the one developed by White [36], "My teacher helps me", is a narrative tool based on six stories that the children have to tell. The results of the study carried out by White enabled children to identify whether they felt supported by their teachers.

Only a few authors have developed standardized instruments in form of questionnaire to study STRs. One of the first instrument of this kind is Feeling about school (FAS) questionnaire, developed by Valeski and Stipek [23]. It measures children's perception of their scholastic skills, their feelings towards their teachers and the way children cope with school. The authors found FAS subscales scores to be positively associated with children's scholastic performance: Children that had a positive experience at school, in fact, were those that obtained better results in mathematics and reading and writing. These children also had a relationship of closeness with their teacher [23].

A more recently developed instrument is the Young Children's appraisals of teacher support (Y-CATS) [22]. The tool's development was based on the literature from the last two decades investigating the nature and dimensionality of the STR from an attachment perspective (e.g., [2, 18, 37 - 39]). The tool is aimed at capturing the features of the quality of the child's relationship with his/her teacher using the dimensions that have already been investigated by teacherreport scales (e.g. STRS [31],): closeness, warmth and autonomy support (which is intended to be the opposite of the STRS' Dependency dimension). A previous study has demonstrated its validity and reliability [40] in the US context, but its psychometric characteristics have not been studied in other Countries yet. Previous research on STRs as perceived by teachers has demonstrated the presence of a cultural influence on the functioning and psychometric features of instruments [41] indicating the need to carefully adapt tools to different application contexts, in order to avoid possible measurement biases.

The aim of the present study is to present the adaptation and validation of the Y-CATS questionnaire to the Italian context.

In particular, we will present the data referring to: i). the descriptive statistics of the measures obtained using YCATS; ii). The criterion validity (significant variations in the instrument's scores reflecting gender and age); iii). The concurrent validity (in terms of the construct of quality of the student-teacher relationship perceived by the teacher); iv). Predictive validity (in terms of emotional problems, behavior problems, hyperactivity and attention deficit, difficulty in social interaction, and pro-social behavior); v). Construct validity (i.e., results emerging from the Exploratory and Confirmatory Factor Analyses).

With respect to the relationship of the Y-CATS subscales scores with other study variables, we have the following expectations: 1). Gender: we expect to find girls generally reporting warmer relationships with teachers, and lower levels of conflict, confirming the findings from past studies, which were conducted using other instruments (e.g., STRS), 2). Age: we expect to confirm the existence of lower levels of conflict and warmer relationships among younger (i.e., kindergarten) children [31, 18, 42]; Teacher-report STR measures: we expect to find substantial correlations between the students' and teachers' perceptions of the quality of the STR; Behavior: we expect to find significant positive correlations between perceived warmth in the relationship with the teacher and prosocial behavior; as regards conflict with teachers, our hypothesis is that students with more conflictual relationships with their teacher will be more likely to present emotional and conduct problems, and ADHD symptoms.

\section{MATERIALS AND METHODS}

\section{Participants}

Participants in the study consisted of 503 students (49\% female) from both kindergarten (33\%) and the first three grades of primary school (67\%). Children were randomly selected from 10 schools (3 kindergarten and 7 primary) which agreed to take part in the research. The total number of schools contacted was 14 . For each child selected, we asked his/her teacher to take part in the research in order to fill in the questionnaire about teacher perception of relationship quality. The families of each selected child were contacted to inform them about the research aims and to collect their informed consent. All but 3 children's parents signed the informed consent form. All of the teachers agreed 
to take part in the research project. The total number of teachers involved was 163 (95\% female).

\section{Measures}

Young Children's Appraisals of Teacher Support (Y-CATS). Y-CATS [22] is a recently developed tool that aims to assess the child's perception of his/her relationship with the teacher with reference to the dimensions typically used in the literature in investigating this construct. These are: Warmth (i.e., closeness and warmth in the relationship); autonomy support (which replaces the Dependency dimension used for example in STRS), and Conflict. Following numerous revisions, the current version of the tool consists of 31 items, of which 14 items assess the way the relationship with the teacher plays a supporting function for the students (e.g., My teacher listens to me); 9 items concern the teacher's ability to stimulate the students' autonomy in class (e.g., My teacher lets me do activities I want to do); 8 items consider the perceived conflict in the relationship (e.g., My teacher gets angry with me). Children are presented with the questions orally, and give a Yes/No answer. Positive answers are scored 1 and negative answers 0 , and the answers are averaged in order to obtain for each dimension a score ranging from 0 to 1 , with higher scores indicating higher levels of Warmth, Autonomy support, and Conflict respectively.

Student-Teacher Relationship Scale (STRS). The Student-Teacher Relationship Scale [31] is a self-report instrument consisting of 28 items developed with reference to Attachment Theory, especially the Attachment Q-set [43]. It is designed to be used with children aged 3 to 8 years (i.e., preschool through third grade). Items are evaluated on a 5-point Likert scale. The final form of the scale presents 3 factors, identified as Conflict, Closeness, and Dependency subscales. The original instrument by Pianta has been adapted and validated to the Italian context [44, 45]. The adapted version consists of 22 items with the same three-dimensional structure of the original instrument: Closeness $(\alpha=.86)$, Conflict $(\alpha=.91)$, and Dependency $(\alpha=.69)$ while the short form consists of 14 items and confirms two dimensions: Closeness $(\alpha=86)$ and Conflict $(\alpha=88)$ [45].

Strength and Difficulties Questionnaire (SDQ). To investigate the behavioral characteristics of the children, we asked each teacher to fill out the Italian version of the Strength and Difficulties Questionnaire [46], which is a validated instrument [47] composed of 25 items that refer to the positive or negative traits of the child's behavior in class. The instrument is divided into five subscales: Emotional Symptoms, Behavioral Problems, Hyperactivity and Attention deficit, Problematic Relationships with Peers, Prosocial Behaviors. The items are evaluated on a three-point Likert scale.

\section{Procedure}

Adaptation to the Italian Language. The scale was translated into Italian following the criteria established by Van de Vijver and Hambleton [48].

We conducted three focus groups with 10 teachers each (28 females, 2 males, average age 38.7, SD = 7.6, range: 24-57). Each group was formed by both kindergarten and primary school teachers. The focus groups were aimed at:

1: Examining the dimensions that characterize the student-teacher relationship from the child's point of view to determine the relevance of an instrument such as the Y-CATS to the Italian context;

2: Verify the readability of the Y-CATS items and their applicability to the Italian educational context.

This preliminary examination specifically showed the non applicability of the "Autonomy support" subscale in the Italian context, since it emerged that, for the type of autonomy recognized and attributed to the child, the questions presented in these terms were not relevant to the Italian school context. More in detail, many components of the focus groups noted that the items of the Autonomy support subscale referred to a kind of classroom organization that was very dissimilar from the Italian one. For instance, in Italy students are not usually allowed to choose the kind of activity to work on during the school hours, or the place in the classroom where to sit, or the children with whom they are invited to work with [49]. Given these differences, it does not make sense to use these items to measure autonomy support in the Italian context.

Data Analysis Strategy. The aim of this study is to adapt and validate the Y-CATS instrument in the Italian context. Given our clustered sampling procedure (i.e., more students share one teacher), the need for multilevel analyses was evaluated computing the design effect. We computed the design effect as recommended by Muthén [50], which is computed using the formula $d=1+\rho(c-1)$, where $\rho$ is the average intraclass correlation and $c$ is the common cluster size (i.e., the average number of students per teacher, 3.09). The design effect was smaller than 2.0 indicating no need 
for multilevel analysis [50].

The analysis procedure was the following: The descriptive statistics were calculated along with the correlation matrix related to the items which composed the tool. We then employed Exploratory factor analysis (EFA) and Confirmatory factor analysis (CFA) to accurately study the Y-CATS data structure. In order to avoid sample-specific results, we split the sample randomly: $50 \%$ of the participants were used as the development sample, and the remaining $50 \%$ as the cross-validation sample. The EFA was conducted on the development sample, followed by CFA. Next, a second CFA was conducted on the second subsample as a cross-validation. The factorial analyses were conducted using M-plus software. Given the two-part nature of the items, we applied weighted least squares mean and variance adjusted (WLSMV) estimator and Geomin rotation. Model fit was evaluated using approximate fit indexes [51]: the comparative fit index (CFI [52]; values above .90 indicate an acceptable fit), and the root mean square error of approximation (RMSEA [53]; values below .08 indicate an acceptable fit). We did not employ the chi-square values to evaluate the fit of the models because of its sensitivity to sample sizes. Reliability levels (Cronbach's alpha) were then calculated for the resulting subscales (Warmth and Conflict). Then we computed the correlations between the scores on the instrument's 2 subscales, and between these scores and the STRS and SDQ subscales. As a final step, we tested for the presence of differences in the two subscales related to gender and type of school.

\section{RESULTS}

\section{Descriptive Statistics}

Table 1 shows the descriptive statistics related to the scores on the items of the Warmth and Conflict subscales, recorded for the whole sample: the scores on the Warmth scale are on average higher and show less dispersion than those on the Conflict scale.

Table 1. Descriptive statistics of the items of Y-CATS.

\begin{tabular}{|c|c|c|c|}
\hline Subscale & Items & M & SD \\
\hline & My teacher... & & \\
\hline Warmth & Y-CATS01 Smiles a lot & .86 & .34 \\
\hline Warmth & Y-CATS02 Listens to me & .95 & .52 \\
\hline Warmth & Y-CATS03 Likes my family & .96 & .20 \\
\hline Warmth & Y-CATS04 Is my friend & .78 & .42 \\
\hline Warmth & Y-CATS05 Says nice things about my work & .93 & .26 \\
\hline Warmth & Y-CATS06 Tells me I am smart & .74 & .44 \\
\hline Warmth & Y-CATS07 Helps me when I do not understand & .94 & .23 \\
\hline Warmth & Y-CATS08 Remembers special days for me & .66 & .47 \\
\hline Warmth & Y-CATS09 Answers my questions & .92 & .28 \\
\hline Warmth & Y-CATS10 Chooses me to be a special helper & .61 & .49 \\
\hline Warmth & Y-CATS11 Likes me & .94 & .24 \\
\hline Warmth & Y-CATS12 Makes the class fun & .87 & .34 \\
\hline Warmth & Y-CATS13 Does activities with me & .67 & .47 \\
\hline Warmth & Y-CATS14 Tells good stories & .91 & .28 \\
\hline Conflict & Y-CATS24 Tells me I do not listen & .33 & .47 \\
\hline Conflict & Y-CATS25 Gets angry with me & .42 & .50 \\
\hline Conflict & ycast26 Doesn't pay attention to me & .24 & .43 \\
\hline Conflict & Y-CATS27 Tells me that I don't try hard enough & .32 & .47 \\
\hline Conflict & ycast 28 Tells me I am going to get in trouble a lot & .28 & .45 \\
\hline Conflict & Y-CATS29 Tells me that I am doing something wrong a lot & .48 & .50 \\
\hline Conflict & Y-CATS30 Tells me to do work that is too hard for me & .45 & .50 \\
\hline Conflict & Y-CATS31 Is mean & .42 & .50 \\
\hline
\end{tabular}

\section{Exploratory Factor Analysis - Development sample}

The preliminary EFA conducted on the development sample revealed a 2-factor solution with a quite satisfactory fit, $\chi^{2}(188)=261.62, p<.001, R M S E A=0.039, C F I=.88$. The eigenvalues of the first two factors were 5.35 and 3.71 . Table 2 shows the factor loadings of the items on the two extracted factors. It can be seen that the resulting factor 
structure replicates the Warmth and Conflict subscales originally proposed quite well [22]. However, five items presented significant cross-loadings with both the extracted factors: items 5, 12, and 13 from the Warmth subscale, and items 26 and 31 from the Conflict subscale. These items were carefully examined and we decided to remove them from the subsequent analyses, because their contribution to the operationalization of the constructs was considered non essential. The EFA was rerun without the removed items and presented an adequate fit: $\chi^{2}(103)=140.25, p<.001$, $R M S E A=0.038, C F I=.92$.

Table 2. Factor loadings EFA and standardized factor loadings CFA of Y-CATS items in development and cross-validation sample.

\begin{tabular}{|c|c|c|c|c|}
\hline \multirow[b]{2}{*}{ Items My teacher... } & \multicolumn{2}{|c|}{ Factors } & \multirow[t]{2}{*}{ CFA Development sample } & \multirow[t]{2}{*}{ CFA Cross-validation sample } \\
\hline & Warmth & Conflict & & \\
\hline 01 Smiles a lot & .736 & \begin{tabular}{|l|l}
-.011 \\
\end{tabular} & .75 & .56 \\
\hline 02 Listens to me & .698 & -.052 & .63 & .58 \\
\hline 03 Likes my family & .528 & .067 & .64 & .77 \\
\hline 04 Is my friend & .420 & .06 & .45 & .53 \\
\hline 05 Says nice things about my work & .433 & -.243 & & \\
\hline 06 Tells me I am smart & .531 & -.068 & .56 & .56 \\
\hline 07 Helps me when I do not understand & .562 & -.16 & .41 & .43 \\
\hline 08 Remembers special days for me & .600 & .151 & .68 & .44 \\
\hline 09 Answers my questions & .576 & -.004 & .56 & .77 \\
\hline 10 Chooses me to be a special helper & .619 & .139 & .56 & .58 \\
\hline 11 Likes me & .554 & -.143 & .67 & .84 \\
\hline 12 Makes the class fun & .739 & .275 & & \\
\hline 13 Does activities with me & .570 & .330 & & \\
\hline 14 Tells good stories & .341 & .071 & .34 & .41 \\
\hline 24 Tells me I do not listen & .002 & .732 & .73 & .68 \\
\hline 25 Gets angry with me & -.027 & .788 & .79 & .87 \\
\hline 26 Doesn't pay attention to me & -.354 & .331 & & \\
\hline 27 Tells me that I don't try hard enough & .063 & .693 & .62 & .48 \\
\hline 28 Tells me I am going to get in trouble a lot & .048 & .672 & .70 & .79 \\
\hline 29 Tells me that I am doing something wrong a lot & -.007 & .691 & .74 & .74 \\
\hline 30 Tells me to do work that is too hard for me & -.045 & .508 & .50 & .44 \\
\hline 31 Is mean & -.366 & .334 & & \\
\hline
\end{tabular}

\section{Confirmatory Factor Analysis - Development Sample}

On the basis of the EFA results, a confirmatory factor analysis was run on the items selected. We tested a two-factor model, with 11 and 6 items loading respectively on the first and second factor. The CFA showed a good fit, with non necessity for the improvement of the model, $\chi^{2}(118)=145.32, p=.04, R M S E A=0.030, C F I=.94$.

\section{Cross-validation of the Model}

Finally, the generalization of the model was tested by fitting it on the cross-validation sample. The model fit of the CFA in the cross-validation sample was slightly poorer, but nonetheless good, $\chi^{2}(118)=147.95, p=.03, R M S E A=$ $0.032, C F I=.94$. Table 2 reports the standardized item loadings for the final model for both the development and crossvalidation sample.

\section{Descriptive Statistics, Reliability and Inter-Correlation of the Y-CATS Subscales}

Mean subscale scores were $0.84(\mathrm{Mdn}=0.91 ; \mathrm{SD}=0.17)$, and $0.38(\mathrm{Mdn}=0.33 ; \mathrm{SD}=0.30)$, for Warmth and Conflict, respectively. Reliability was examined for both the subscales, using Cronbach's alpha. For the Warmth subscale, Cronbach's alpha was .60 , while for the Conflict subscale it was .70 . The two subscales did not show a significant correlation with each other $(r=-.08)$. 
Table 3. Pearson correlations between Y-CATS, STRS-SF and SDQ $(\mathbf{N}=\mathbf{5 0 3})$.

\begin{tabular}{|c|c|c|c|c|c|c|c|c|c|}
\hline & \multicolumn{2}{|c|}{ Y-CATS } & \multicolumn{2}{c|}{ STRS-SF } & \multicolumn{5}{c|}{ SDQ } \\
\hline & Warmth & Conflict & Closeness & Conflict & Emotional & Conduct & Hyperactivity & Peer & Prosocial \\
\hline Y-CATS & & & & & & & & & \\
\hline Warmth & - & -.08 & $.16^{* *}$ & -.04 & .03 & -.06 & $-.11^{*}$ & -.05 & $.13^{* *}$ \\
\hline Conflict & & - & $-.16^{* *}$ & $.22^{* *}$ & $.11^{*}$ & $.20^{* *}$ & $.31^{* *}$ & .09 & $-.13^{* *}$ \\
\hline STRS & & & & & & & & & \\
\hline Closeness & & - & $-.40^{* *}$ & & & & & & \\
\hline Conflict & & & - & & & & & & \\
Note: ${ }^{*} \mathrm{p}<.05 ; * \mathrm{p}<.01$.
\end{tabular}

\section{Correlations between Y-CATS Subscales and STRS}

Significant correlations emerged between the raw scores of the Warmth and Conflict subscales and STRS subscales scores (Table 3). In particular, Warmth was found to be significantly positively correlated with Closeness $(\mathrm{r}=.16)$, while Conflict showed a significant positive correlation with STRS-Conflict subscale $(r=.22)$ and a negative correlation with the STRS-Closeness subscales $(\mathrm{r}=-.16)$.

\section{Correlations between Y-CATS Subscales and SDQ}

As an indication of predictive validity of the Y-CATS, we computed Pearson correlations between Warmth and Conflict subscales with SDQ subscales (Table 3). Warmth subscales showed a significant positive correlation with the SDQ Prosocial behaviors subscale, and was negatively correlated with SDQ Hyperactivity. The Conflict subscale was positively correlated with 3 SDQ subscales (i.e., Emotional problems, Conduct problems, and Hyperactivity) and negatively correlated with Prosocial behaviors.

\section{Differences Related to Gender and Type of School}

In order to determine whether there were differences in the Warmth and Conflict subscales related to the children's gender or to the type of school attended (i.e., primary or Kindergarten) we conducted ANOVAs using gender and type of school as $I V \mathrm{~s}$.

We found a significant gender effect for both Warmth $(F(1,501)=4.92, p<.05)$ and Conflict $(F(1,501)=18.70$, $p<.01)$ subscales. Girls presented higher levels of Warmth $(M=.86, S D=.15)$ than boys $(M=.83, S D=.18)$. On the other hand, Conflict subscale presented higher levels for boys $(M=.44, S D=.31)$ than for girls $(M=.32, S D=.29)$. Concerning school type, we found that children from kindergarten reported higher levels of Conflict, $F(1,502)=26.80$, $p<.01$ (kindergarten: $M=.48, S D=.32$; primary school: $M=.33, S D=.29$ ).

\section{DISCUSSION}

The descriptive statistics show that the mean level and score distribution of the Y-CATS subscales are very similar to those found by Mantzicopoulos and Neuharth-Pritchett [22] in their original instrument development paper, with higher levels of perceived Warmth and lower levels of Conflict.

The preliminary Exploratory Factorial Analysis shows quite a satisfactory adaptation of the two-factor model, which adequately replicates the two Warmth and Conflict sub-scales of the instrument's original version. However, five items $(5,12,13,26,31)$ are associated to both the factors extracted. For this reason, we was decided to eliminate them in order to perform an additional EFA, which, when carried out, proved to present adequate adaptation indicators. The items eliminated were seen to be potentially ambiguous when referring to the Italian context. In fact, according to an ecological perspective $[27,54]$ child development necessarily takes place within interconnected systems, and the student-teacher relationship can only be understood by examining the individual characteristics of the students and the teachers globally, as well as those of the environments where the interactions occur. The Warmth scale saw the elimination of items 5, 12 and 13: while n. 5 ("My teacher says nice things about my work") explicitly refers to positive semantic categories used by the teacher concerning the person's work ("very nice", "my work"), n. 12 ("My teacher makes the class fun") is not actually relevant to the representation of the positive qualities of a personal relationship. In this form, it could instead express a favorable opinion of the general way of managing the group: the item's ambiguity emerges from the simultaneous positive association with both factors. Finally, item n. 13 ("My teacher does activities with me") concerns aspects of the relationship that do not necessarily have positive connotations, being presented in 
neutral terms. As regards the items that were eliminated from the Conflict scale $(26,31)$, they may appear ambiguous compared to the phrasing of item n. 31: "My teacher is mean". Perceiving teachers as being more strict does not necessarily express the perception of something negative in the relationship.

The model thus obtained (26 items organized in two sub-scales, Warmth and Conflict) then underwent a Confirmatory Factorial Analysis, revealing a good adaptation. This version of the instrument showed adequate levels of reliability.

The instrument's concurrent validity was verified by examining the correlations between the Y-CATS and STRS subscales, which confirmed the expectations. Warmth has a significant correlation with STRS-Closeness; Conflict correlates with STRS-Closeness and STRS-Conflict. The moderate degree of correlation observed is confirmed in the literature $[21,37,40]$, which also shows the possible fluctuation of correlation strength according to the level of school attended. It is interesting to note how the Conflict dimension of the Y-CATS is the only one to correlate with both STRS dimensions. Therefore, only the conflict dimension of the STR would have its correlations confirmed by the previous literature.

The instrument's predictive validity was assessed in terms of the possibility of revealing the manifestation of problem behavior among students, by examining the correlations with the scores obtained on the SDQ: the results show significant correlations between the Warmth scale and the Hyperactivity and Prosocial Behavior subscales. Students who describe the relationship with the teacher as marked by warmth and closeness would tend to display fewer problems of inattention and hyperactivity and more attitudes of openness towards others and prosociality.

The Conflict subscale shows a positive correlation with Emotional Conduct, Hyperactivity, and a negative correlation with the Prosocial Behavior subscale. These results reflect what is known in the literature about the association between conflict in the student-teacher relationship and the manifestation of behavioral or conduct problems [39]. The quality of the student-teacher relationship is, in fact, closely connected in a broader way to levels of aggressiveness and to basic social skills, as well as academic achievement $[55,56]$. The instrument's power to predict behavioral issues therefore seems to be confirmed, although the correlations are not particularly strong.

Furthermore, a higher sensibility of the Conflict subscale of the Y-CATS can be observed, since it correlates with all SDQ subscales except the Peer Problems subscale which, contrary to our expectations, is not correlated with the YCATS's Warmth subscale. This might be explained by the fact that the subscale measures the relationship with the child's peers and not with teachers or other adults.

Therefore, the Conflict subscale seems to be the dimension that satisfies the requirements of concurrent and predictive validity in a manner that is more constant and evident, as compared to the Warmth dimension.

As far as gender is concerned, average male scores were higher on the Conflict subscale, while females scored higher on Warmth. The gender effect is significant in both these scales, confirming the tendencies found in the literature about gender differences in relation to the (positive or negative) quality of the relationship with the teacher [3, 22, 23].

Concerning the teacher's gender, it was not possibile to investigate its effect on the students' perception of the STR, given that most of the teacher sample (95\%) consisted of females. However, the gender proportion in our sample is not dissimilar from the proportion of female teachers in Italian primary school [57].

As regards variations in scores related to the school attended, kindergarten children tend to have a stronger perception of conflict and negativity in the relationship with the teacher, aspects also found in the literature [7, 34, 58].

\section{LIMITATIONS}

The study conducted revealed some limitations, to be considered in any future application of the instrument.

Firstly, the original version of the insturment (with three dimensions: "Warmth"; "Conflict", “Autonomy support”) proved not to be very applicable in the Italian context: the dimension of Autonomy support, as operationalized in the items of the original version, is, in fact, not adequate to the educational expectations typical of the Italian teaching situation. The aspects investigated by the items concern experiences of autonomy that are not envisaged in the normal Italian classroom. A two-factor model was therefore proposed: one related to the components of warmth and affection perceived in the relationship with the teacher ("Warmth"), the other related to negative components of conflict in the relationship ("Conflict"). However, given the widely recognized importance of the Autonomy support dimension in school adjustment, future work is needed to develop and reintroduce in the Italian version of the Y-CATS a subscale 
measuring this dimension,.

Furthermore, a refinement of the instrument was proposed, with the elimination of items in which the factorial saturation did not allow for a clear association with one of the factors extracted (items 5, 12, 13, 26 and 31). The confirmatory factor analysis shows a model that differs in part from the original three-factor instrument. Another limitation concerns the instrument's reliability, as the levels of which (Cronbach's alpha) are only slightly above the threshold of acceptability; similar observations can be made about concurrent and predictive validity. In fact, the significant correlations found between the Y-CATS and STRS and SDQ scores are of a moderate size.

\section{CONCLUSION}

Despite the above limitations, in our opinion, Y-CATS still remains a useful instrument for the investigation of the student-teacher relationship, since at the present time in the literature there are no similar instruments to assess this construct from the student's point of view. There is, however, wide recognition [21] of how important it is to study the quality of the relationship between teacher and student in order to be able to foresee or infer the presence of general issues related to the student's behavior, or to possible anxiety and internalizing disorders.

One aspect to consider in order to better understand the limitations revealed may also concern the difficulty of anchoring the kind of request made by the items to a broader time scale: the child is in fact asked to disengage from the relationship with the teacher underway at the present time, to retrieve representations and memories of other periods experienced.

In view of the importance of being able to measure the self-perception of the quality of the relationship with the teacher, we feel that despite the critical issues emerging, the potential for application of this instrument must be recognized. Undoubtedly, it is an instrument that needs further refinement with a better adaptation to the context of application.

\section{APPENDIX}

Y-CATS items by subscale.

\begin{tabular}{|c|c|}
\hline Items & Item content \\
\hline \multicolumn{2}{|c|}{ Warmth } \\
\hline 1 & $\begin{array}{l}\text { My teacher smiles a lot } \\
\text { La mia maestra sorride molto }\end{array}$ \\
\hline 2 & $\begin{array}{l}\text { My teacher listens to me } \\
\text { La mia maestra mi ascolta }\end{array}$ \\
\hline 3 & $\begin{array}{l}\text { My teacher likes my family } \\
\text { Alla mia maestra piace la mia famiglia }\end{array}$ \\
\hline 4 & $\begin{array}{l}\text { My teacher is my friend } \\
\text { La mia maestra è mia amica }\end{array}$ \\
\hline 5 & $\begin{array}{l}\text { My teacher tells me I am smart } \\
\text { La mia maestra dice che sono intelligente }\end{array}$ \\
\hline 6 & $\begin{array}{l}\text { My teacher helps me when I do not understand } \\
\text { La mia maestra mi aiuta quando non ho capito }\end{array}$ \\
\hline 7 & $\begin{array}{l}\text { My teacher remembers special days for me } \\
\text { La mia maestra si ricorda i giorni speciali per me }\end{array}$ \\
\hline 8 & $\begin{array}{l}\text { My teacher answers my questions } \\
\text { La mia maestra risponde alle mie domande }\end{array}$ \\
\hline 9 & $\begin{array}{l}\text { My teacher chooses me to be a special helper } \\
\text { La mia maestra mi sceglie come aiutante speciale }\end{array}$ \\
\hline 10 & $\begin{array}{l}\text { My teacher likes me } \\
\text { Piaccio alla mia maestra }\end{array}$ \\
\hline 11 & $\begin{array}{l}\text { My teacher tells good stories } \\
\text { La mia maestra racconta belle storie }\end{array}$ \\
\hline \multicolumn{2}{|c|}{ Conflict } \\
\hline 12 & $\begin{array}{l}\text { My teacher tells me I do not listen } \\
\text { La mia maestra mi dice che non ascolto }\end{array}$ \\
\hline 13 & $\begin{array}{l}\text { My teacher gets angry with me } \\
\text { La mia maestra si arrabbia con me }\end{array}$ \\
\hline
\end{tabular}




\$SSHGI contd.....
\begin{tabular}{|l|l|}
\hline Items & Item content \\
\hline Warmth & $\begin{array}{l}\text { My teacher tells me that I don't try hard enough } \\
\text { La mia maestra mi dice che non mi sforzo abbastanza }\end{array}$ \\
\hline 14 & $\begin{array}{l}\text { My teacher tells me I am going to get in trouble a lot } \\
\text { La mia maestra mi dice spesso che mi sto per mettere nei guai }\end{array}$ \\
\hline 15 & $\begin{array}{l}\text { My teacher tells me that I am doing something wrong a lot } \\
\text { La mia maestra mi dice spesso che sto facendo qualcosa di sbagliato }\end{array}$ \\
\hline 17 & $\begin{array}{l}\text { My teacher tells me to do work that is too hard for me } \\
\text { La mia maestra mi dice di fare un lavoro che è troppo difficile per me }\end{array}$ \\
\hline
\end{tabular}

Italian items are printed in italics.

\section{REFERENCES}

[1] Hughes K, Bullock A, Coplan RJ. A person-centred analysis of teacher-child relationships in early childhood. Br J Educ Psychol 2014; 84(Pt 2): 253-67. [http://dx.doi.org/10.1111/bjep.12029] [PMID: 24116925]

[2] Birch SH, Ladd GW. Childrens interpersonal behaviors and the teacher-child relationship. Dev Psychol 1998; 34(5): 934-46. [http://dx.doi.org/10.1037/0012-1649.34.5.934] [PMID: 9779740]

[3] Hamre BK, Pianta RC. Early teacher-child relationships and the trajectory of childrens school outcomes through eighth grade. Child Dev 2001; 72(2): 625-38. [http://dx.doi.org/10.1111/1467-8624.00301] [PMID: 11333089]

[4] Rudasill KM, Rimm-Kaufmann SE. Teacher-child relationship quality: The role of child temperament and teacher-child interactions. Early Child Res Q 2009; 24(2): 107-20.

[http://dx.doi.org/10.1016/j.ecresq.2008.12.003]

[5] Howes C, Matheson CC. Contextual constraints on the concordance of mother-child and teacher-child relationship. In: Pianta RC, Ed. Beyond the parent: the role of other adults in children lives. San Francisco: Jossey-Bass 1992; pp. 25-40. [http://dx.doi.org/10.1002/cd.23219925704]

[6] Pianta RC. Enhancing relationships between children and teachers. Washington, DC: American Psychological Association 1999. [http://dx.doi.org/10.1037/10314-000]

[7] Baker JA. Contributions of teacher-child relationships to positive school adjustment during elementary school. J Sch Psychol 2006; 44(3): 211-29. [http://dx.doi.org/10.1016/j.jsp.2006.02.002]

[8] Quaglia R, Gastaldi FG, Prino LE, Pasta T, Longobardi C. The pupil-teacher relationship and gender differences in Primary School. Open Psychol J 2013; 6(1): 69-75.

[http://dx.doi.org/10.2174/1874350101306010069]

[9] Birch SH, Ladd GW. The teacher-child relationship and children's early school adjustment. J Sch Psychol 1997; 35(1): 61-79. [http://dx.doi.org/10.1016/S0022-4405(96)00029-5]

[10] Burchinal MR, Peisner-Feinberg E, Pianta R, Howes C. Development of academic skills from preschool through second grade: Family and classroom predictors of developmental trajectories. J Sch Psychol 2002; 40(5): 415-36. [http://dx.doi.org/10.1016/S0022-4405(02)00107-3]

[11] Murray C, Murray KM, Waas GA. Child and teacher reports of teacher-student relationships: Concordance of perspectives and associations with school adjustment in urban kindergarten classrooms. J Appl Dev Psychol 2008; 29(1): 49-61. [http://dx.doi.org/10.1016/j.appdev.2007.10.006]

[12] O’Connor R, McCartney K. Examining teacher-child relationships and achievement as part of an ecological model of development. Am Educ Res J 2007; 44(2): 340-69.

[http://dx.doi.org/10.3102/0002831207302172]

[13] Pianta RC, Stuhlman MW, Hamre BK. How schools can do better: fostering stronger connections between teachers and students. New Dir Youth Dev 2002; 2002(93): 91-107. [http://dx.doi.org/10.1002/yd.23320029307] [PMID: 12040815]

[14] Ahnert L, Pinquart M, Lamb ME. Security of childrens relationships with nonparental care providers: a meta-analysis. Child Dev 2006; 77(3): 664-79. [http://dx.doi.org/10.1111/j.1467-8624.2006.00896.x] [PMID: 16686794]

[15] Henricsson L, Rydell AM. Children with behaviour problems: The influence of social competence and social relations on problem stability, school achievement and peer acceptance across the first six years of school. Infant Child Dev 2006; 15(4): 347-66. [http://dx.doi.org/10.1002/icd.448]

[16] Pasta T, Mendola M, Longobardi C, Prino LE, Gastaldi FG. Attributional style of children with and without specific learning disability. Electron J Res Educ Psychol 2013; 11(3): 649-64. [http://dx.doi.org/10.14204/ejrep.31.13064] 
[17] Prino LE, Pasta T, Gastaldi FG, Longobardi C. The effect of autism spectrum disorders, down syndrome, specific learning disorders and hyperactivity and attention deficits on the student-teacher relationship. Electron J Res Educ Psychol 2016; 14(1): 89-106. [http://dx.doi.org/10.14204/ejrep.38.15043]

[18] Saft EW, Pianta RC. Teachers' perceptions of their relationships with students: Effects of child age, gender, and ethnicity of teachers and children. Sch Psychol Q 2001; 16(2): 125-41. [http://dx.doi.org/10.1521/scpq.16.2.125.18698]

[19] Mashburn AJ, Hamre BK, Downer JT, Pianta RC. Teacher and classroom characteristics associated with teachers' ratings of prekindergartners' relationships and behaviors. J Psychoed Assess 2006; 24(4): 367-80. [http://dx.doi.org/10.1177/0734282906290594]

[20] O’Connor EE, Dearing E, Collins BA. Teacher-child relationship and behavior problem trajectories in elementary school. Am Educ Res J 2011; 48(1): 120-62. [http://dx.doi.org/10.3102/0002831210365008]

[21] Harrison LJ, Clarke L, Ungerer JA. Children's drawings provide a new perspective on teacher-child relationship quality and school adjustment. Early Child Res Q 2007; 22(1): 55-71. [http://dx.doi.org/10.1016/j.ecresq.2006.10.003]

[22] Mantzicopoulos P, Neuharth-Pritchett S. Development and validation of a measure to assess head start children's appraisals of teacher support. J Sch Psychol 2003; 41(6): 431-51. [http://dx.doi.org/10.1016/j.jsp.2003.08.002]

[23] Valeski TN, Stipek DJ. Young childrens feelings about school. Child Dev 2001; 72(4): 1198-213. [http://dx.doi.org/10.1111/1467-8624.00342] [PMID: 11480942]

[24] Howes C. Attachment relationships in the context of multiple caregivers. In: Cassidy J, Shaver PR, Eds. Handbook of attachment: Theory, research, and clinical applications. New York, NY: Guilford 1999; pp. 671-87.

[25] Davis HA. Conceptualizing the role and influence of student-teacher relationships on children's social and cognitive development. Educ Psychol 2003; 38(4): 207-34. [http://dx.doi.org/10.1207/S15326985EP3804_2]

[26] Cassidy J. Emotion regulation: influences of attachment relationships. Monogr Soc Res Child Dev 1994; 59(2-3): 228-49. [http://dx.doi.org/10.1111/j.1540-5834.1994.tb01287.x] [PMID: 7984163]

[27] Bronfenbrenner U. The ecology of human development: experiments by nature and design. Cambridge, MA: Harvard University Press 1979.

[28] Bronfenbrenner U, Morris PA. The bioecological model of human development. Handbook of child psychology. In: Lerner RM, Ed. Theoretical models of human development. 6th ed. Hoboken, NJ: Wiley 2006; 1: pp. 793-828.

[29] Mantzicopoulos P. Conflictual relationships between kindergarten children and their teachers: Associations with child and classroom context variables. J Sch Psychol 2005; 43(5): 425-42. [http://dx.doi.org/10.1016/j.jsp.2005.09.004]

[30] Pianta RC, Hamre B, Stuhlman M. Relationships between teachers and children. In: Reynolds WM, Miller GE, Weiner IB, Eds. Educational Psychology Handbook of psychology. Hoboken, NJ: Wiley 2003; pp. 199-234.

[31] Pianta RC. Student-teacher relationship scale: professional manual. Lutz, FL: Psychological Assessment Resources 2001.

[32] Burchinal M, Howes C, Pianta R, et al. Predicting child outcomes at the end of kindergarten from the quality of pre-kindergarten teacher-child interactions and instruction. Appl Dev Sci 2008; 12(3): 140-53. [http://dx.doi.org/10.1080/10888690802199418]

[33] Buyse E, Verschueren K, Doumen S, Van Damme J, Maes F. Classroom problem behavior and teacher-child relationships in kindergarten: the moderating role of classroom climate. J Sch Psychol 2008; 46(4): 367-91. [http://dx.doi.org/10.1016/j.jsp.2007.06.009] [PMID: 19083364]

[34] Doumen S, Verschueren K, Buyse E, Germeijs V, Luyckx K, Soenens B. Reciprocal relations between teacher-child conflict and aggressive behavior in kindergarten: a three-wave longitudinal study. J Clin Child Adolesc Psychol 2008; 37(3): 588-99. [http://dx.doi.org/10.1080/15374410802148079] [PMID: 18645749]

[35] Fury G, Carlson EA, Sroufe LA. Childrens representations of attachment relationships in family drawings. Child Dev 1997; 68(6): 1154-64. [http://dx.doi.org/10.2307/1132298] [PMID: 9418231]

[36] White KM. "My teacher helps me": assessing teacher-child relationships from the child's perspective. J Res Child Educ 2016; 30(1): 29-41. [http://dx.doi.org/10.1080/02568543.2015.1105333]

[37] Pianta RC, Nimetz SL. Relationships between children and teachers: Associations with classroom and home behavior. J Appl Dev Psychol 1991; 12(3): 379-93. [http://dx.doi.org/10.1016/0193-3973(91)90007-Q]

[38] Pianta RC, Nimetz SL, Bennett E. Mother-child relationships, teacher-child relationships, and school outcomes in preschool and kindergarten. Early Child Res 1997; 12(3): 263-80.

[http://dx.doi.org/10.1016/S0885-2006(97)90003-X] 
[39] Pianta RC, Steinberg MS, Rollins KB. The first two years of school: teacher-child relationships and deflections in children's classroom adjustment. Dev Psychopathol 1995; 7(02): 295-312. [http://dx.doi.org/10.1017/S0954579400006519]

[40] Spilt JL, Koomen HM, Mantzicopoulos PY. Young children's perceptions of teacher-child relationships: an evaluation of two instruments and the role of child gender in kindergarten. J Appl Dev Psychol 2010; 31(6): 428-38. [http://dx.doi.org/10.1016/j.appdev.2010.07.006]

[41] Milatz A, Glüer M, Harwardt-Heinecke E, Kappler G, Ahnert L. The student-teacher relationship scale revisited: testing factorial structure, measurement invariance and validity criteria in German-speaking samples. Early Child Res Q 2014; 29(3): 357-68. [http://dx.doi.org/10.1016/j.ecresq.2014.04.003]

[42] Justice LM, Cottone EA, Mashburn A, Rimm-Kaufman SE. Relationships between teachers and preschoolers who are at risk: Contribution of children's language skills, temperamentally based attributes, and gender. Early Educ Dev 2008; 19(4): 600-21. [http://dx.doi.org/10.1080/10409280802231021]

[43] Waters E, Deane KE. Defining and assessing individual differences in attachment relationships In: Q-methodology and the organization of behavior in infancy and early childhood In Bretherton I, Waters E, Eds Growing points of attachment theory and research Monogr Soc Res Child . 1985; 50: pp. (1-2)41-65.

[44] Fraire M, Longobardi C, Prino LE, Sclavo E, Settanni M. Examining the student-teacher relationship scale in the italian context: a factorial validity study. Electron J Res Educ Psychol 2013; 11(3): 851-82. [http://dx.doi.org/10.14204/ejrep.31.13068]

[45] Settanni M, Longobardi C, Sclavo E, Fraire M, Prino LE. Development and psychometric analysis of the student-teacher relationship scale short form. Front Psychol 2015; 6: 898 . [http://dx.doi.org/10.3389/fpsyg.2015.00898] [PMID: 26167156]

[46] Goodman R. The strengths and difficulties questionnaire: a research note. J Child Psychol Psychiatry 1997; 38(5): 581-6. [http://dx.doi.org/10.1111/j.1469-7610.1997.tb01545.x] [PMID: 9255702]

[47] Tobia V, Gabriele MA, Marzocchi GM. Norme italiane dello Strengths and Difficulties Questionnaire (SDQ): Il comportamento dei bambini italiani valutato dai loro insegnanti. Disturbi di attenzione e iperattività 2011;6: 167-74.

[48] Van de Vijver FJ, Hambleton RK. Translating tests: Some practical guide-lines. Eur Psychol 1996; 1(2): 89-99. [http://dx.doi.org/10.1027/1016-9040.1.2.89]

[49] MIUR - Ministero dell'Istruzione, Università e Ricerca [Italian Ministry of Education]. National guidelines for primary school curricula. Rome, IT: MIUR. (2013).

[50] Muthén B. Methodological issues in random coefficient growth modeling using a latent variable framework: Applications to the development of heavy drinking. Multivariate Applications in Substance Use Research 2000; pp. 113-40.

[51] Ropovik I. A cautionary note on testing latent variable models. Front Psychol 2015; 6: 1715. [http://dx.doi.org/10.3389/fpsyg.2015.01715] [PMID: 26594192]

[52] Bentler PM. Comparative fit indexes in structural models. Psychol Bull 1990; 107(2): 238-46. [http://dx.doi.org/10.1037/0033-2909.107.2.238] [PMID: 2320703]

[53] Steiger JH. Tests for comparing elements of a correlation matrix. Psychol Bull 1980; 87: 245-51. [http://dx.doi.org/10.1037/0033-2909.87.2.245]

[54] Bronfenbrenner U, Morris PA. The ecology of developmental processes. Handbook Child Psychol 1998; 1: 993-1028.

[55] Pianta RC, Walsh D. High-risk children in the school Creating sustaining Relationships. New York: Routledge 1996.

[56] Pianta RC, Steinberg M. Teacher-child relationships and the process of adjusting to school. New Dir Child Adolesc Dev 1992; 1992(57): 61-80. [http://dx.doi.org/10.1002/cd.23219925706]

[57] OECD. Education at a Glance 2012: OECD Indicators. OECD Publishing 2012.

[58] Longobardi C, Prino LE, Marengo D, Settanni M, . Student-teacher relationships as a protective factors for school adjustment during the transition from middle to high school. Front Psychol 2016; 7: 1988. [http://dx.doi.org/10.3389/fpsyg.2016.01988]

(C) Longobardi et al.; Licensee Bentham Open

This is an open access article licensed under the terms of the Creative Commons Attribution-Non-Commercial 4.0 International Public License (CC BY-NC 4.0) (https://creativecommons.org/licenses/by-nc/4.0/legalcode), which permits unrestricted, non-commercial use, distribution and reproduction in any medium, provided the work is properly cited. 